\title{
Chemistry on a global stage
}

\author{
The International Year of Chemistry gives chemists a chance to raise the profile of their subject.
}

In 1995 the Royal Society of Chemistry (RSC) carried out research into public attitudes to chemistry in four English cities, including Huddersfield and London. Most people's perceptions of chemistry, it found, were based on their experiences at school, and most recalled school chemistry as boring. Moreover, most of the primary school teachers surveyed by the RSC saw chemistry as "a difficult and boring subject, pursued by intelligent but unimaginative people" 1,2 .

\section{The chemistry community has} much to offer when it comes to addressing global issues such as sustainable energy, climate change and the provision of clean food and water

Much has changed in both chemistry and public attitudes to science (and research into public attitudes to science ${ }^{3}$ ) in the 16 years since the 'Huddersfield experiment', but raising the profile and popularity of science subjects among school pupils (and their parents and teachers) remains as big a challenge as ever, which is why the international chemistry community - in the shape of the International Union of Pure and Applied Chemistry (IUPAC) - has persuaded the United Nations to declare that 2011 will be the International Year of Chemistry ${ }^{4}$. IYC2011 follows recent years of biodiversity (2010), astronomy (2009), planet Earth (2008) and physics (2005).

The year 2011 has historical resonance for chemists, being the 100th anniversary of the founding of the International Association of Chemical Societies (the forerunner of IUPAC) and, more pertinently, of Marie Curie winning the Nobel Prize for Chemistry for her work on radium and polonium. Only three other women have won this prize: Curie's daughter Irène Joliot-Curie (1935), the English crystallographer Dorothy Hodgkin (1964), and the Israeli structural biologist Ada Yonath (2009), who will be one of the speakers at the official launch of IYC2011 in
Paris at the end of January. (The situation is even worse in physics, with Curie being one of just two women to have won the prize.)

The theme of the year will be 'Chemistry - our life, our future', and the prospectus for the year opens with a good case for the ubiquity and importance of chemistry: "All known matter — gas, liquid and solid - is composed of the chemical elements or of compounds made from those elements. Humankind's understanding of the material nature of our world is grounded in our knowledge of chemistry. Indeed, all living processes are controlled by chemical reactions." If physicists argue that this is a rather limited view of matter, their chemical colleagues can retort that it took a chemist and 100,000 gallons of tetrachloroethylene, a common dry-cleaning fluid, to detect solar neutrinos for the first time ${ }^{5}$.

The three overarching goals for the year seem somewhat similar to each other - to increase the public appreciation of chemistry in meeting world needs; to encourage interest in chemistry among young people; and to generate enthusiasm for the future of chemistry - but that will not be a problem if everyone involved in IYC2011 manages to convey the scientific breadth of their subject and its relevance to our daily lives. As pointed out in Nature Chemistry, the chemistry community has much to offer when it comes to addressing global issues such as sustainable energy, climate change and the provision of clean food and water ${ }^{6}$, and these topics feature prominently in the plans for IYC2011.

And although the nanoscale is not explicitly mentioned in the prospectus, chemists are active in many areas of nanoscience and nanotechnology including, among other things, selfassembly, molecular electronics, soft lithography, DNA nanotechnology, sensing and biomedical applications of nanoparticles.

The chemistry community seems to have become more concerned about its public profile in recent years ${ }^{7}$, in the UK at least, with the RSC going into PR overdrive in its efforts to raise the profile of chemistry in the British media: the society's press office has been busy putting out press releases on both lightweight topics, such as the perfect cup of tea, and heavyweight subjects such as science policy and education. Some chemists might have rolled their eyes at some of the lightweight releases (or "stunts" as the society's media relations manager has called them), but the RSC has estimated that its press coverage had "an advertizing equivalent value of almost $£ 2$ million” in one year ${ }^{8}$. Ironically, it was the RSC rolling its eyes earlier this year when it denounced the government for using a "lazy stereotype of the chemist as unhinged scientist" in an anti-drugs campaign fronted by a Crazy Chemist ${ }^{9,10}$.

\section{Chemists are active in many areas of nanotechnology including self-assembly, molecular electronics, soft lithography, DNA nanotechnology and sensing}

Judging if a year of chemistry (or biodiversity, or astronomy) has been a success will not be easy (or facile, to use a word found in many chemistry papers). Many factors influence whether, for example, a student decides to study chemistry at school or university. If student numbers increase, who can say that a particular campaign made a decisive difference? And if numbers fall, who's to say that they would not have fallen further without various activities? But that should not deter scientific communities from making the case for their subjects at every possible opportunity.

\footnotetext{
References

1. Public Perceptions of Chemistry (RSC, 1995).

2. Science and Society (House of Lords Select Committee on Science and Technology, 2000); available at http://go.nature.com/oS2974

3. Toumey, C. Nature Nanotech. 6, 3-4 (2011).

4. www.chemistry2011.org

5. Davis, R., Harmer, D. S. \& Hoffman, K. C. Phys. Rev. Lett. 20, 1205-1209 (1968).

6. Nature Chem. 3, 1 (2011).

7. Nature Chem. 2, 599 (2010).

8. www.absw.org.uk/news-events/features/447-making-chemistry-cool

9. www.direct.gov.uk/en/N11/Newsroom/DG_180662

10. www.bbc.co.uk/news/education-11330173
} 